\title{
The prognostic value of left ventricular systolic function measured by tissue Doppler imaging in septic shock
}

\author{
Li Weng ${ }^{2 \dagger}$, Yong-tai Liu ${ }^{1 *+}$, Bin Du², Jian-fang Zhou², Xiao-xiao Guo ${ }^{2}$, Jin-min Peng ${ }^{2}$, Xiao-yun $\mathrm{Hu}^{2}$, \\ Shu-yang Zhang ${ }^{1}$, Quan Fang ${ }^{1}$ and Wen-ling Zhu ${ }^{1}$
}

\begin{abstract}
Introduction: Left ventricular (LV) dysfunction is common in septic shock. Its association with the clinical outcome is still controversial. Tissue Doppler imaging (TDI) is a useful tool to quantify LV function; however, little knowledge is available about the prognostic value of these TDI variables in septic shock. Therefore, we performed this prospective study to determine the role of TDI variables in septic shock.

Methods: Patients with septic shock in a medical intensive care unit were studied with transthoracic echocardiography with TDI within 24 hours after the onset of septic shock. Baseline clinical, laboratory, and echocardiographic variables were prospectively collected. Independent predictors of 90-day mortality were analyzed with the Cox regression model.

Results: During a 20-month period, 61 patients were enrolled in the study. The 90-day mortality rate was 39\%; the mean APACHE IV score was 84 (68 to 97). Compared with survivors, nonsurvivors exhibited significantly higher peak systolic velocity measured at the mitral annulus (Sa) (11.0 (9.1 to 12.5$)$ versus 7.8 (5.5 to 9.0$) \mathrm{cm} / \mathrm{sec}$; $P<$ 0.0001), lower $\mathrm{PaO}_{2} / \mathrm{FiO}_{2}$ (123 (83 to 187) versus 186 (142 to 269) $\mathrm{mm} \mathrm{Hg} ; P=0.002$ ], higher heart rate (120 (90 to 140) versus 103 (90 to 114) beats/min; $P=0.004$ ], and ahigher dose of norepinephrine (0.6 (0.2 to 1.0) versus 0.3 (0.2 to 0.5$) \mu \mathrm{g} / \mathrm{kg} / \mathrm{min} ; P=0.007$ ]. In the multivariate analysis, Sa $>9 \mathrm{~cm} / \mathrm{sec}$ (hazard ratio (HR), 5.559; $95 \%$ confidence interval $(\mathrm{Cl}), 2.160$ to $14.305 ; P<0.0001)$, dose of norepinephrine $(\mathrm{HR}, 1.964 ; 95 \% \mathrm{Cl}, 1.338$ to $2.883 ; P=$ $0.001)$, and $\mathrm{PaO}_{2} / \mathrm{FiO}_{2}(\mathrm{HR}, 0.992 ; 95 \% \mathrm{Cl}, 0.984$ to $0.999 ; P=0.031)$ remain independent predictors of 90-day mortality in septic-shock patients.
\end{abstract}

Conclusions: Our study demonstrated that LV systolic function as determined by TDI, in particular, Sa, might be associated with mortality in patients with septic shock.

\section{Introduction}

Although left ventricular (LV) depression in sepsis was first reported decades ago [1], it has not been well recognized until the recent widespread use of echocardiography in the intensive care unit (ICU) [2]. A variety of echocardiographic parameters have been developed to assess LV function [3]. Among these parameters, ejection fraction (EF) is most commonly used to evaluate

\footnotetext{
* Correspondence: ataiever@gmail.com

† Contributed equally

'Department of Cardiology, Peking Union Medical College Hospital, Peking Union Medical College and Chinese Academy of Medical Sciences, 1

Shuaifuyuan, Dongcheng district, Beijing, 100730, China

Full list of author information is available at the end of the article
}

LV systolic function, although studies exploring its association with clinical outcome have demonstrated conflicting results in high-risk patients, especially in patients with septic shock [2].

Tissue Doppler imaging (TDI) has been shown to be useful for quantifying global systolic and diastolic LV function [4-6]. The peak systolic velocity measured at the mitral annulus $(\mathrm{Sa})$ reflects the long-axis systolic motion of the ventricle, whereas the early diastolic velocity of the mitral annulus (Ea) reflects the rate of myocardial relaxation. Both $\mathrm{Sa}$ and $\mathrm{Ea}$ have been demonstrated as useful tools to predict prognosis in a variety of cardiovascular diseases [7]. However, the
C Biomed Central

(c) 2012 Liu et al.; licensee BioMed Central Ltd. This is an open access article distributed under the terms of the Creative Commons Attribution License (http://creativecommons.org/licenses/by/2.0), which permits unrestricted use, distribution, and reproduction in any medium, provided the original work is properly cited. 
prognostic value of the TDI variables in septic shock requires further clarification.

Therefore, we performed a prospective, observational study to evaluate the prognostic significance of TDI variables in septic shock.

\section{Materials and methods Patients}

The study was performed in a nine-bed medical ICU of a university teaching hospital. Between January 2010 and August 2011, all patients admitted for septic shock that developed within 24 hours before ICU admission were prospectively screened for eligibility. Sepsis, severe sepsis, and septic shock were defined according to consensus definition [8] (see Additional file 1 Figure S2), and the differentiation between infectious and noninfectious etiologies was made at the discretion of the ICU consultant. In patients with multiple episodes of septic shock, only the first episode was included in this study.

Exclusion criteria included age younger than 18 years; pregnancy; presence of moderate to severe valvular heart disease; patients or their relatives declined participation; suboptimal echocardiograms; postthoracic operation; documented myocardial infarction at any point in the medical history; and a decision of withdraw or withhold life-sustaining therapy.

Baseline clinical variables during the first 24 hours after admission (day 1) were collected prospectively, including age, gender, comorbidities, hemodynamic parameters, vasopressor or inotropic dose, Acute Physiology and Chronic Health Evaluation (APACHE) IV score [9], and Sequential Organ Failure Assessment (SOFA) score [10].

\section{Echocardiographic examination}

Two-dimensional conventional Doppler echocardiography and TDI studies were performed with commercially available equipment (Vivid I; GE Vingmed Ultrasound, Tirat Hacarmel, Israel). All studies were performed and reviewed by cardiologists with advanced training in echocardiography.

The transthoracic echocardiographic examination was performed within 24 hours after the onset of septic shock at the first day of ICU stay (day 1). LV end-diastolic volume (LVEDV), LV end-systolic volume (LVESV), and LV ejection fraction (LVEF) were assessed by using the modified biplane Simpson equation in the apical four- and two-chamber views, according to the American Society of Echocardiography Guidelines [11]. Mitral inflow was assessed with pulsed-wave Doppler echocardiography from the apical four-chamber view. The Doppler beam was aligned parallel to the direction of flow, and a 1- to 2-mm sample volume was placed between the tips of mitral leaflets during diastole [12].
From the mitral inflow profile, the E- and A-wave velocity and the E/A velocity ratio were measured. At least three consecutive beats were measured, and the average value was taken. In patients with tachycardia, the fused EA wave was considered an E wave to calculate the E/ Ea.

TDI was performed at the apical four-chamber view for the long-axis motion of the heart $[13,14]$. Twodimensional echocardiography with color-TDI imaging was performed. The imaging angle was adjusted to ensure a parallel alignment of the sampling window with the myocardial segment of interest. Gain settings, filters, pulse repetitive frequency, sector size, and depth were adjusted to optimize color saturation. The frame rate was adjusted to $>100$. At least three consecutive beats were stored, and the images were digitized and analyzed off-line by EchoPac software (EchoPac 6.3.6; Vingmed-General Electric, Horten, Norway). Pulse-Doppler sample volume was placed at the septal and lateral $\mathrm{MV}$ annulus to obtain the average value of systolic ( $\mathrm{Sa}$ ) and early diastolic velocity (Ea) (see Additional file 1 Figure S2).

The intraobserver and interobserver variability in the measurements of Sa were $1.8 \%$ and $4.2 \%$, respectively.

\section{Follow-up}

Follow-up was performed for 90 days after the onset of septic shock. The primary end point was 90-day allcause mortality, defined as death within 90 days after onset of septic shock. Death was identified from hospital records or telephone interviews with relatives.

The Institutional Review Board of Peking Union Medical College Hospital approved this study protocol. Written informed consent was obtained from either the patients or their authorized relatives.

\section{Statistical analysis}

Deviations from a gaussian distribution were tested by the Kolmogorov-Smirnov test. Continuous variables were presented as median (25th to 75 th percentiles). Categoric variables were expressed as percentages of the group from which they were derived. Continuous variables were compared with the use of the Student $t$ test or Mann-Whitney test. Categoric variables were compared with the $\chi^{2}$ test or Fisher Exact test. Linear regression was used to investigate the correlation between EF and Sa. A receiver-operating characteristic (ROC) curve analysis was performed to determine the cutoff value of Sa for the prediction of 90-day mortality. The optimal cut-off value was defined as the point at which the value of "sensitivity + specificity - 1" was maximum (Youden index $[15,16]$ ).

A survival curve was performed by using the KaplanMeier method, and mortality rates were compared 
according to the cut-off value of Sa by using the logrank test.

Cox proportional hazards regression model was used to estimate the risk of death by multivariate analysis (backward stepwise selection method with probability for the removal of 0.10 ) for the whole population. The multivariate analysis selection criterion from the univariate analysis was $P$ value $<0.05$ and absence of collinearity. Collinearity was defined as variance inflation factor (VIF) > 10 by using linear regression analysis.

All analysis was performed by using software (SPSS for Windows 11.5; SPSS, Chicago, IL, USA). Statistical significance was considered at $P<0.05$.

\section{Results}

\section{Baseline characteristics}

During the study period, from January 2010 to August 2011, 132 patients with septic shock were eligible for assessment. Seventy-one were excluded in the final analysis, including consent refusal $(n=24)$, severe regurgitation $(n=10)$, postthoracic operation $(n=5)$, withheld or withdrawn therapy $(n=14)$, and suboptimal echocardiograms $(n=18)$. As a result, 61 patients were analyzed. Patients excluded had higher proportion of coronary heart disease. No significant difference was noted in other baseline characteristics between patients excluded and included (see Additional file 1 Table S1).

The 33 (54\%) men had a median age of 68 (52 to 77) years, and an APACHE IV score of 84 (68 to 97). Twenty-two patients died during ICU stay, and 24 patients died at 90 days after the onset of septic shock, with a 90 -day all-cause mortality of $39 \%$. Five patients died within 48 hours of ICU admission. A total of 36 (59\%) patients had documented comorbidities, including coronary heart disease (13\%), hypertension (46\%), and diabetes (28\%). For all patients, no episode of active ischemia was documented in the last 3 months before inclusion. The most common infection was pneumonia (56\%). All patients required vasoactive medications to maintain blood pressure, and all were mechanically ventilated because of acute lung injury. Table 1 compared baseline clinical variables on ICU admission (day 1) between survivors and nonsurvivors. Nonsurvivors had significantly lower $\mathrm{PaO}_{2} / \mathrm{FiO}_{2}$ (123 (83 to 187 ) versus 186 (142 to 269$) \mathrm{mm} \mathrm{Hg} P=0.002$ ) than did survivors.

Table 2 summarized hemodynamic and echocardiographic parameters on day 1 . Heart rate was significantly higher in nonsurvivors (120 (90 to 140) versus 103 (90 to 114 ) beats/min; $P=0.004]$. Forty-nine $(80 \%)$ patients received norepinephrine infusion at a median dose of 0.5 (0.2 to 0.7$) \mu \mathrm{g} / \mathrm{kg} / \mathrm{min}$. The dose of norepinephrine was significantly higher in nonsurvivors $(0.6$ (0.2 to 1.0 ) versus 0.3 (0.2 to 0.5$) \mu \mathrm{g} / \mathrm{kg} / \mathrm{min} ; P=0.007$. Twenty-seven $(44 \%)$ patients were treated with dopamine, the median dose being 6.0 (5.0 to 10.0) $\mu \mathrm{g} /$ $\mathrm{kg} / \mathrm{min}$. During the study periods, one patient was treated with dobutamine $(5 \mu \mathrm{g} / \mathrm{kg} / \mathrm{min})$, and another, with epinephrine $(0.5 \mu \mathrm{g} / \mathrm{kg} / \mathrm{min})$.

\section{Echocardiographic variables}

Five patients were in atrial fibrillation at the time of echocardiography study. Ten of 61 patients had fused E A wave, six in the group of survivors. Sa was significantly lower in the survivors group than in the nonsurvivors (7.8 (5.5 to 9.0) versus 11.0 (9.1 to 12.5$) \mathrm{cm} / \mathrm{sec}$; $P<0.0001)$, with a mean value of $9.0(6.6$ to 11.0$) \mathrm{cm} /$ sec for the whole cohort. Sixteen (27\%) patients had an LVEF $<50 \%$. LVEF values for survivors and nonsurvivors were $56 \%$ (36\% to $65 \%$ ) and $63 \%$ (52\% to $66 \%$ ), respectively. Other parameters, including those evaluating diastolic function, did not show any statistical difference between survivors and nonsurvivors (Table 2). A moderate correlation between LVEF and Sa was identified with linear regression (Figure 1).

The ability of Sa to predict 90-day mortality according to an ROC curve is shown in Figure 2, the area under the curve being 0.83 . With a cut-off value of $9 \mathrm{~cm} / \mathrm{sec}$, the sensitivity and specificity of Sa to predict 90-day mortality was $75 \%$ and $86 \%$, respectively. Patients with a higher Sa value $(>9 \mathrm{~cm} / \mathrm{sec})$ had a significantly higher mortality rate $(75 \%$ versus $17 \% ; P<0.0001$; log-rank $=$ 24.03; $P<0.0001$ ) (Table 2 and Figure 3 ).

\section{Predictors of 90-day mortality in septic shock patients}

In the final multivariate analysis, Sa $>9 \mathrm{~cm} / \mathrm{sec}$ remained the strongest independent predictor of 90-day mortality in septic shock patients (HR, 5.559; 95\% CI, 2.160 to 14.305 ; Wald, $12.652 ; P<0.0001)$. Moreover, norepinephrine dose and $\mathrm{PaO}_{2} / \mathrm{FiO}_{2}$ were also independent predictors, whereas heart rate did not exhibit any predictive value. Subgroup analysis showed that, in patients without a history of coronary heart disease, a Sa value of $>9 \mathrm{~cm} / \mathrm{sec}$ was still an independent predictor of 90-day mortality (HR, 4.546; 95\% CI, 1.749 to 11.819 ; Wald, 9.651; $P=0.002$ ) (Table 3).

\section{Discussion}

The major finding of our study was that increased $\mathrm{Sa}$ is an independent predictor of 90-day mortality in patients with septic shock.

In the landmark study of Parker et al. [1], 10 of the 20 patients with septic shock exhibited global hypokinesia and ventricular dilation during the first 48 hours after admission. Contrary to common sense, the authors found significantly impaired LV systolic function in survivors compared with nonsurvivors. Subsequent studies $[17,18]$ demonstrated similar reversible global hypokinesia by echocardiography. Vieillard-Baron and colleagues 
Table 1 Baseline characteristics and comparison between survivors and nonsurvivors at the onset of septic shock (day 1)

\begin{tabular}{|c|c|c|c|}
\hline & $\begin{array}{l}\text { Survivors } \\
(n=37)\end{array}$ & $\begin{array}{l}\text { Nonsurvivors } \\
(n=24)\end{array}$ & $P$ value \\
\hline \multicolumn{4}{|l|}{ Characteristics } \\
\hline Age, years & $68(49-76)$ & $74(61-82)$ & 0.167 \\
\hline Male, $n(\%)$ & $18(49)$ & $15(63)$ & 0.289 \\
\hline $\mathrm{BMI}, \mathrm{kg} / \mathrm{m}^{2}$ & $23(21-25)$ & $23(20-26)$ & 0.732 \\
\hline APACHE IV score & $79(66-94)$ & $93(69-99)$ & 0.339 \\
\hline APACHE IV predicted mortality, $\%$ & $28(17-53)$ & $48(35-61)$ & 0.039 \\
\hline SOFA score & $10(8-12)$ & $10(8-12)$ & 0.222 \\
\hline $\mathrm{PaO}_{2} / \mathrm{FiO}_{2}, \mathrm{~mm} \mathrm{Hg}$ & $186(142-269)$ & $123(83-187)$ & 0.002 \\
\hline SOFA cardiovascular score & $4(4-4)$ & $4(4-4)$ & 0.911 \\
\hline Days on vasoactive medications & $5(3-9)$ & $7(4-9)$ & 0.340 \\
\hline ICU LOS, days & $12(8-22)$ & $12(4-20)$ & 0.515 \\
\hline Hospital LOS, days & $29(17-49)$ & $17(6-52)$ & 0.150 \\
\hline \multicolumn{4}{|l|}{ Comorbidities } \\
\hline Coronary heart disease, $n(\%)$ & $6(16)$ & $2(8)$ & 0.373 \\
\hline Hypertension, n (\%) & $18(49)$ & $10(42)$ & 0.593 \\
\hline Diabetes, $n(\%)$ & $12(32)$ & $5(21)$ & 0.324 \\
\hline Chronic renal failure, $n(\%)$ & $6(16)$ & $2(8)$ & 0.373 \\
\hline \multicolumn{4}{|l|}{ Primary diagnosis of infection } \\
\hline Pneumonia, $n(\%)$ & $18(49)$ & $16(67)$ & 0.166 \\
\hline Bacteremia, $n(\%)$ & $5(14)$ & $2(8)$ & 0.535 \\
\hline Peritonitis, $n$ (\%) & $5(13)$ & $1(4)$ & 0.231 \\
\hline Others, $n(\%)$ & $9(24)$ & $5(21)$ & 0.751 \\
\hline \multicolumn{4}{|l|}{ Laboratory data } \\
\hline Lactate, $\mathrm{m} M$ & $1.75(1.30-2.88)$ & $2.00(1.80-3.98)$ & 0.095 \\
\hline $\mathrm{WBC}, \times 10^{9} / \mathrm{L}$ & $11.36(7.18-19.99)$ & $12.07(6.91-18.90)$ & 0.623 \\
\hline Procalcitonin, ng/ml & $2.01(0.59-7.40)$ & $1.50(0.53-5.71)$ & 0.435 \\
\hline $\mathrm{cTnl}, \mu \mathrm{g} / \mathrm{L}$ & $0.17(0.06-1.14)$ & $0.15(0.04-0.93)$ & 0.952 \\
\hline $\mathrm{CKMB}, \mu \mathrm{g} / \mathrm{L}$ & $1.80(0.60-3.83)$ & $1.65(1.03-4.90)$ & 0.455 \\
\hline NTproBNP, pg/ml & $4,072.00(2,006.50-11,885.50)$ & $3,710.00(1,361.50-10,618.25)$ & 0.693 \\
\hline
\end{tabular}

APACHE, Acute Physiology And Chronic Health Evaluation; BMI, body mass index; Hospital LOS, hospital length of stay; SOFA, Sequential Organ Failure Assessment.

[17] observed global hypokinesia in 26 of 67 patients. Moreover, LVEF was compromised in survivors during the first 24 hours $(49 \% \pm 18 \%$ versus $55 \% \pm 15 \%)$ [17]. In another study performed over a period of 5 years [18], survivors showed evidence of septic myocardial dysfunction, as suggested by compromised LVEF $(43.9 \%$ $\pm 16.4 \%$ versus $52.0 \% \pm 14.0 \%)$ and higher LVEDV $(75.3$ $\pm 20.1 \mathrm{ml} / \mathrm{m}^{2}$ versus $\left.64.9 \pm 25.0 \mathrm{ml} / \mathrm{m}^{2} ; P<0.05\right)$. However, similar to our study, the difference in LVEF between survivors and nonsurvivors was not significantly different.

The linear correlation between $\mathrm{Sa}$ and ejection in our study was similar to that of a previous study [5]. Unlike LVEF, Sa was a sensitive marker of LV systolic function in patients with cardiovascular disease, which showed that Sa could predict clinical outcome in a more sensitive manner than could the LVEF [7]. In a study of hypertrophic cardiomyopathy, TDI revealed myocardial contractive abnormalities before any clinical presentations [19]. In our study, Sa appeared to be a more-sensitive predictor of mortality than was the ejection fraction. However, the value of Sa remains to be validated in more patient populations [7,19-21], especially in critically ill patients. Moreover, unlike patients with cardiovascular diseases in whom a lower Sa was associated with lower survival rate, survivors with septic shock exhibited significantly decreased $\mathrm{Sa}$, as seen in our study.

Many hypotheses have been proposed for myocardial depression in septic shock [2,22]. However, most of them could not explain why survivors exhibited moremarked myocardial depression. Levy et al. [23] demonstrated myocardial hibernation in sepsis by using magnetic resonance imaging, positron emission tomography, and single-photon emission computed tomography imaging. Myocardial hibernation is the best mechanism to 
Table 2 Baseline hemodynamic and echocardiographic data of survivors and nonsurvivors at the onset of septic shock (day 1)

\begin{tabular}{|c|c|c|c|}
\hline & $\begin{array}{l}\text { Survivors } \\
(n=37)\end{array}$ & $\begin{array}{l}\text { Non- } \\
\text { survivors } \\
(n=24)\end{array}$ & $\begin{array}{l}P \\
\text { value }\end{array}$ \\
\hline \multicolumn{4}{|l|}{ Hemodynamic parameters } \\
\hline Heart rate, beats/min & $103(90-114)$ & $120(90-140)$ & 0.004 \\
\hline $\begin{array}{l}\text { Mean arterial pressure, mm } \\
\mathrm{Hg}\end{array}$ & $76(74-83)$ & $74(70-82)$ & 0.189 \\
\hline $\begin{array}{l}\text { Central venous pressure, } \\
\mathrm{mm} \mathrm{Hg}\end{array}$ & $16(12-17)$ & $14(11-19)$ & 0.911 \\
\hline Dopamine, $n(\%)$ & $17(46)$ & $10(42)$ & \\
\hline Dose, $\mu \mathrm{g} / \mathrm{kg} / \mathrm{min}$ & $5.0(4.0-10.0)$ & $6.0(4.5-10.0)$ & 0.836 \\
\hline Norepinephrine, $n$ (\%) & $30(81)$ & $19(79)$ & \\
\hline Dose, $\mu \mathrm{g} / \mathrm{kg} / \mathrm{min}$ & $0.3(0.2-0.5)$ & $0.6(0.2-1.0)$ & 0.007 \\
\hline $\begin{array}{l}\text { Balance on day } 0, \mathrm{ml} / 24 \\
\text { hours }\end{array}$ & $\begin{array}{l}1,180(445- \\
2,140)\end{array}$ & $\begin{array}{l}1,850(15- \\
3,004)\end{array}$ & 0.640 \\
\hline \multicolumn{4}{|l|}{ Echocardiographic data } \\
\hline \multicolumn{4}{|l|}{ Systolic parameters } \\
\hline LVEDV, $\mathrm{ml}$ & $72(54-98)$ & $63(56-78)$ & 0.110 \\
\hline LVESV, ml & $30(20-52)$ & $26(19-34)$ & 0.169 \\
\hline LVEF biplane, \% & $56(36-65)$ & $63(52-66)$ & 0.111 \\
\hline $\begin{array}{l}\text { LVEF biplane < 50\%, } n \\
\text { (\%) }\end{array}$ & $12(33)$ & $4(17)$ & 0.234 \\
\hline $\mathrm{Sa}, \mathrm{cm} / \mathrm{sec}$ & $7.8(5.5-9.0)$ & $\begin{array}{l}11.0(9.1- \\
12.5)\end{array}$ & $\begin{array}{l}< \\
0.0001\end{array}$ \\
\hline $\mathrm{Sa}>9 \mathrm{~cm} / \mathrm{s}, n(\%)$ & $6(17)$ & $18(75)$ & $\begin{array}{l}< \\
0.0001\end{array}$ \\
\hline \multicolumn{4}{|l|}{ Diastolic parameters } \\
\hline$E / A$ & $0.9(0.7-1.4)$ & $0.7(0.6-1.2)$ & 0.171 \\
\hline $\mathrm{Ea}, \mathrm{cm} / \mathrm{sec}$ & $8.3(5.8-10.0)$ & $7.0(6.0-11.0)$ & 0.634 \\
\hline $\mathrm{Ea}<8 \mathrm{~cm} / \mathrm{sec}, n(\%)$ & $15(42)$ & $12(52)$ & 0.429 \\
\hline $\mathrm{E} / \mathrm{Ea}$ & $11.1(8.5-14.6)$ & $\begin{array}{l}11.1(6.6- \\
14.1)\end{array}$ & 0.206 \\
\hline
\end{tabular}

$\mathrm{E}$, peak velocity of early diastolic transmitral flow; Ea, early diastolic velocity of the mitral annulus; $\mathrm{E} / \mathrm{A}$, the ratio of mitral valve peak $\mathrm{E}$-wave and peak $\mathrm{A}$ wave velocity; EDT, deceleration time of mitral E wave; LVEDV, left ventricular end-diastolic volume; LVEF, left ventricle ejection fraction; LVESV, left ventricular end-systolic volume; Sa, peak systolic velocity measured at mitral annulus.

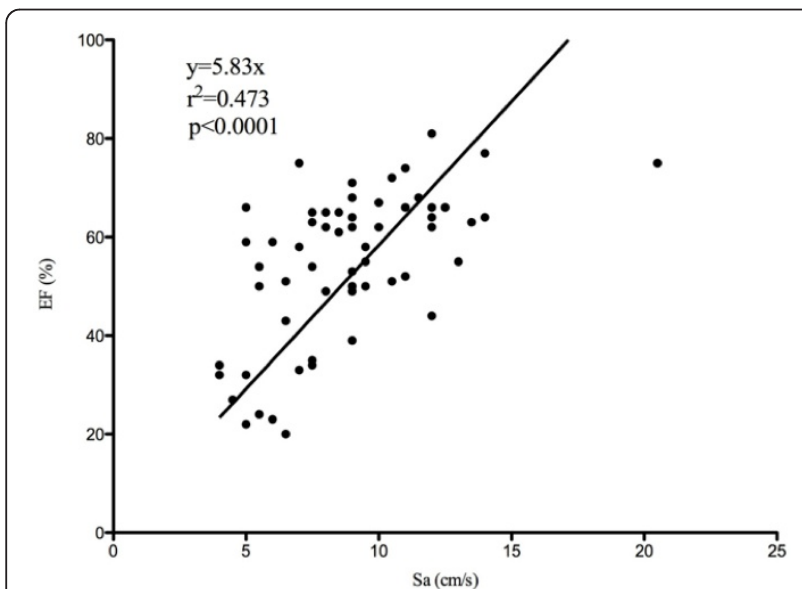

Figure 1 The line regression between left ventricular ejection fraction (LVEF) and mitral annulus (Sa).

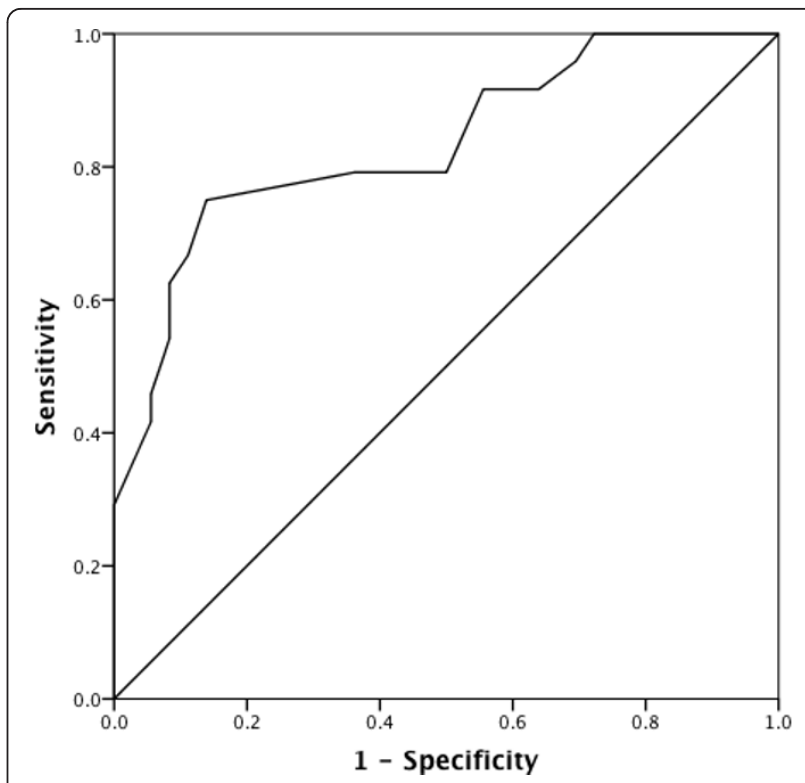

Figure 2 Receiver-operating characteristic (ROC) curve for predicting 90 -day mortality by using the peak systolic velocity measured at the mitral annulus (Sa). Area under the curve is 0.83 .

preserve cardiac myocytes by downregulation of oxygen consumption and energy requirements. It is an adaptive response to maintain myocardial viability for prevention of cell-death pathway activation and to aid the future full recovery. The slightly increased cardiac biomarkers (that is, cTnI) in the study population also support that physical myocardial injury is negligible. Instead, the heart was injured "functionally." Such a potential beneficial response must be based on an assumption that tissue perfusion might be maintained with the depressed heart. With a close look at our data, lactate, a good marker of tissue perfusion [24], was not elevated, despite myocardial depression. However, serial echocardiographs

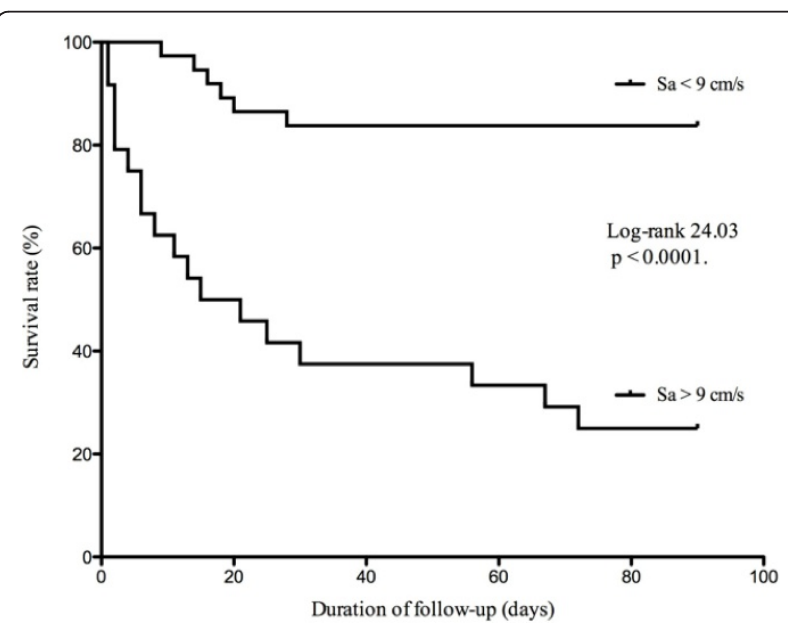

Figure 3 The 90-day mortality in the study population classified according to the peak systolic velocity measured at mitral annulus $(\mathrm{Sa})<9 \mathrm{~cm} / \mathrm{sec}$ or $\mathrm{Sa}>9 \mathrm{~cm} / \mathrm{sec}$ 
Table 3 Multivariate analysis for predictors of death in patients with septic shock

\begin{tabular}{cccc}
\hline & \multicolumn{3}{c}{ Multivariate analysis } \\
& Hazard ratio $(\mathbf{9 5 \%}$ & $\begin{array}{c}\text { Wald } \\
\text { stat. }\end{array}$ & P value \\
\hline $\mathrm{PaO}_{2} / \mathrm{FiO}_{2}$ & $0.992(0.984-0.999)$ & 4.628 & 0.031 \\
$\begin{array}{c}\text { Norepinephrine, } \mu \mathrm{g} / \mathrm{kg} / \\
\mathrm{min}\end{array}$ & $1.964(1.338-2.883)$ & 11.898 & 0.001 \\
$\mathrm{Sa}>9 \mathrm{~cm} / \mathrm{sec}$ & $5.559(2.160-14.305)$ & 12.652 & $<$ \\
& & & 0.0001 \\
\hline
\end{tabular}

were performed for only some of our patients; further serial study was warranted to support this hypothesis.

Persistent vasoplegia might be another explanation for our finding. Although the Sa has advantages over previously used measures of LV systolic function, such as LVEF, it still is load dependent, afterload especially $[25,26]$. In the study of Robotham et al. [26], the same level of LVEF may correspond to very different level of intrinsic LV contractility. For instance, an LVEF of 55\% may correspond to severe impressed intrinsic LV contractility in the presence of decreased vascular tone. It would not be surprising to find relatively normal or supernormal Sa in nonsurvivors in our study, which reflected a hyperkinetic state associated with persistent and profound vasoplegia that, in turn, could be a marker of sustained cytokine release. This kind of persistent vasoplegia was associated with a high mortality rate, which is consistent with our findings.

Sturgess et al. [27] also reported the role of TDI to assess LV function in septic shock patients. They failed to find any difference in LV systolic function between survivors and nonsurvivors. This might be explained by the small sample size $(n=21)$ and high prevalence of cardiac diseases (43\%) in the study population. Myocardial infarction may influence systolic and diastolic TDI values, as previously described by Alam et al. [28]. We also included patients with coronary heart disease in our study, but patients with myocardial infarction were excluded. Furthermore, after the exclusion of patients with coronary heart disease, the predictive value of Sa still remained. Similar to the study of Sturgess [27], Landesberg et al. [29] did not find evidence of LV systolic dysfunction in survivors. However, only $62 \%$ in the study population had septic shock. This, in addition to the imbalanced distribution of septic shock between survivors and nonsurvivors (57\% versus $72 \% ; P=0.012$ ), precluded direct comparison between their study result and that of our study.

In our cohort of patients, MAP was maintained at a higher level than that recommended by the guideline [30]. This can be explained by the high prevalence of hypertension in the study population. Although no evidence suggested the benefit of hyperdynamic support, Dünser et al. [31] reported that the time spent below the MAP of $75 \mathrm{~mm} \mathrm{Hg}$ would increase the risk of subsequent renal-replacement therapy. Such findings suggest the importance of addressing ischemic acute renal failure in the absence of frank hypotension [32]. Accordingly, we try to individualize the target of blood pressure in our patients, based on usual level. The study of Vieillard-Baron et al. [17] suggested that the increased norepinephrine loads necessary to maintain high blood pressures were likely to cause LV hypokinesia. However, the dose of norepinephrine to maintain blood pressure in our groups was lower in survivors (0.3 (0.2 to 0.5$)$ versus $0.6(0.2$ to 1.0$) \mu \mathrm{g} / \mathrm{kg} / \mathrm{min}$ ], who had a higher incidence of LV hypokinesia. In the final multivariate analysis, even after adjustment for norepinephrine treatment, the prognostic value of Sa still attained statistical significance.

\section{Limitations}

First, the sample size in our study was relatively small, but the robust association between $\mathrm{Sa}$ and mortality rate suggests that this was not just an accidental finding. Possible selection biases might exist because more patients were excluded than were studied. However, the baseline characteristics, except for coronary heart disease, did not show significant differences between the patients excluded and included. Second, this study is a single-center study. Our local management strategy may influence the patient's outcome, which might preclude the generalization of the study findings. Third, the potential confounding factors for TDI variables were not explored in this study. A more-detailed study focusing on these confounding factors is highly desirable. Fourth, correlation between TDI variables and blood flowderived parameters was not performed because pulmonary artery catheters were inserted in only half of the study population.

\section{Conclusion}

Our study demonstrated that LV systolic function, as determined by TDI, in particular, by Sa, might be associated with mortality in patients with septic shock. Concerning the limitations as discussed earlier, further studies are warranted to confirm our findings.

\section{Key messages}

- In patients with septic shock, compared with nonsurvivors, survivors exhibited more marked myocardial depression.

- Evaluation of LV function by TDI, in particular, by Sa, might be associated with mortality in patients with septic shock. 


\section{Additional material}

Additional file 1: Supplement. Supplement to Methods Results.

\begin{abstract}
Abbreviations
APACHE: Acute Physiology And Chronic Health Evaluation; E: peak velocity of early diastolic transmitral flow; Ea: early diastolic velocity measured at the mitral annulus; EF: ejection fraction; ICU: intensive care unit; LV: left ventricular; LVEDV: LV end-diastolic volume; LVESV: LV end-systolic volume; PCWP: pulmonary capillary wedge pressure; ROC: receiver-operating characteristic; SIRS: systemic inflammatory response syndrome; SOFA: Sequential Organ Failure Assessment; TDI: tissue Doppler imaging; Sa: peak systolic velocity measured at the mitral annulus.
\end{abstract}

\section{Author details}

'Department of Cardiology, Peking Union Medical College Hospital, Peking Union Medical College and Chinese Academy of Medical Sciences, 1 Shuaifuyuan, Dongcheng district, Beijing, 100730, China. ${ }^{2}$ Medical ICU, Peking Union Medical College Hospital, Peking Union Medical College and Chinese Academy of Medical Sciences, 1 Shuaifuyuan, Dongcheng District, Beijing, 100730, China.

\section{Authors' contributions}

$Y L, L W, B D, J Z, X G, J P, X H, S Z, Q F$, and $W Z$ participated in the design of the study and performed the statistical analysis. $Y L, L W$, and BD conceived of the study and participated in its design and coordination. All authors read and approved the final manuscript.

\section{Competing interests}

The authors declare that they have no competing interests. All authors report no funding for support of this work.

Received: 22 December 2011 Revised: 29 February 2012

Accepted: 3 May 2012 Published: 3 May 2012

\section{References}

1. Parker MM, Shelhamer JH, Bacharach SL, Green MV, Natanson C, Frederick TM, Damske BA, Parrillo JE: Profound but reversible myocardial depression in patients with septic shock. Ann Intern Med 1984, 100:483-490

2. Hunter JD, Doddi M: Sepsis and the heart. Br J Anaesthes 2010, 104:3-11.

3. Dittoe N, Stultz D, Schwartz BP, Hahn HS: Quantitative left ventricular systolic function: from chamber to myocardium. Crit Care Med 2007, 35: S330-S339.

4. Gulati VK, Katz WE, Follansbee WP, Gorcsan J: Mitral annular descent velocity by tissue Doppler echocardiography as an index of global left ventricular function. Am J Cardiol 1996, 77:979-984.

5. Yu CM, Lin H, Yang H, Kong SL, Zhang Q, Lee SW: Progression of systolic abnormalities in patients with "isolated" diastolic heart failure and diastolic dysfunction. Circulation 2002, 105:1195-1201.

6. Paulus WJ, Tschope C, Sanderson JE, Rusconi C, Flachskampf FA, Rademakers FE, Marino P, Smiseth OA, De Keulenaer G, Leite-Moreira AF, Borbély A, Edes I, Handoko ML, Heymans S, Pezzali N, Pieske B, Dickstein K, Fraser AG, Brutsaert DL: How to diagnose diastolic heart failure: a consensus statement on the diagnosis of heart failure with normal left ventricular ejection fraction by the Heart Failure and Echocardiography Associations of the European Society of Cardiology. Eur Heart J 2007, 28:2539-2550.

7. Yu C, Sanderson J, Marwick TH, Oh J: Tissue Doppler imaging: a new prognosticator for cardiovascular diseases. J Am Coll Cardiol 2007 49:1903-1914.

8. Bone RC, Balk RA, Cerra FB, Dellinger RP, Fein AM, Knaus WA, Schein RM, Sibbald WJ: Definitions for sepsis and organ failure and guidelines for the use of innovative therapies in sepsis: The ACCP/SCCM Consensus Conference Committee, American College of Chest Physicians/Society of Critical Care Medicine. Chest 1992, 101:1644-1655.
9. Zimmerman JE, Kramer AA, McNair DS, Malila FM: Acute Physiology and Chronic Health Evaluation (APACHE) IV: hospital mortality assessment for today's critically ill patients. Crit Care Med 2006, 34:1297-1310.

10. Vincent JL, Moreno R, Takala J, Willatts $S$, de Mendonça A, Bruining H, Reinhart CK, Suter PM, Thijs LG: The SOFA (Sepsis-related Organ Failure Assessment) score to describe organ dysfunction/failure, on behalf of the Working Group on Sepsis-Related Problems of the European Society of Intensive Care Medicine. Intensive Care Med 1996, 22:707-710.

11. Lang RM, Bierig M, Devereux RB, Flachskampf FA, Foster E, Pellikka PA, Picard MH, Roman MJ, Seward J, Shanewise JS, Solomon SD, Spencer KT, Sutton MS, Stewart WJ, Chamber Quantification Writing Group; American Society of Echocardiography's Guidelines and Standards Committee; European Association of Echocardiography: Recommendations for chamber quantification: a report from the American Society of Echocardiography's Guidelines and Standards Committee and the Chamber Quantification Writing Group, developed in conjunction with the European Association of Echocardiography, a branch of the European Society of Cardiology. J Am Soc Echocardiogr 2005, 18:1440-1463.

12. Quiñones MA, Otto CM, Stoddard M, Waggoner A, Zoghbi WA Echocardiography DQTFotNaSCotASo: Recommendations for quantification of Doppler echocardiography: a report from the Doppler Quantification Task Force of the Nomenclature and Standards Committee of the American Society of Echocardiography. J Am Soc Echocardiogr 2002, 15:167-184.

13. Yu CM, Wang Q, Lau CP, Tse HF, Leung SK, Lee KL, Tsang V, Ayers G: Reversible impairment of left and right ventricular systolic and diastolic function during short-lasting atrial fibrillation in patients with an implantable atrial defibrillator: a tissue Doppler imaging study. Pacing Clin Electrophysiol 2001, 24:979-988.

14. Pai RG, Gill KS: Amplitudes, durations, and timings of apically directed left ventricular myocardial velocities: II. Systolic and diastolic asynchrony in patients with left ventricular hypertrophy. J Am Soc Echocardiogr 1998, 11:112-118.

15. Fluss R, Faraggi D, Reiser B: Estimation of the Youden Index and its associated cutoff point. Biometr J Biometrische Z 2005, 47:458-472.

16. Schisterman EF, Perkins NJ, Liu A, Bondell H: Optimal cut-point and its corresponding Youden Index to discriminate individuals using pooled blood samples. Epidemiology 2005, 16:73-81.

17. Vieillard-Baron A, Caille V, Charron C, Belliard G, Page B, Jardin F: Actual incidence of global left ventricular hypokinesia in adult septic shock. Crit Care Med 2008, 36:1701-1706.

18. Jardin F, Fourme $T$, Page $B$, Loubières $Y$, Vieillard-Baron $A$, Beauchet $A$, Bourdarias JP: Persistent preload defect in severe sepsis despite fluid loading: a longitudinal echocardiographic study in patients with septic shock. Chest 1999, 116:1354-1359.

19. Nagueh SF, Bachinski LL, Meyer D, Hill R, Zoghbi WA, Tam JW, Quiñones MA, Roberts R, Marian AJ: Tissue Doppler imaging consistently detects myocardial abnormalities in patients with hypertrophic cardiomyopathy and provides a novel means for an early diagnosis before and independently of hypertrophy. Circulation 2001, 104:128-130.

20. Chahal NS, Lim TK, Jain P, Chambers JC, Kooner JS, Senior R: Normative reference values for the tissue Doppler imaging parameters of left ventricular function: a population-based study. Eur J Echocardiogr 2010, 11:51-56.

21. Wang M, Yip GW, Wang AY, Zhang Y, Ho PY, Tse MK, Lam PK, Sanderson JE: Peak early diastolic mitral annulus velocity by tissue Doppler imaging adds independent and incremental prognostic value. $J$ Am Coll Cardiol 2003, 41:820-826.

22. Vieillard-Baron A: Septic cardiomyopathy. Ann Intensive Care 2011, 1:6.

23. Levy RJ, Piel DA, Acton PD, Zhou R, Ferrari VA, Karp JS, Deutschman CS: Evidence of myocardial hibernation in the septic heart. Crit Care Med 2005, 33:2752-2756.

24. Nguyen HB, Corbett SW, Steele R, Banta J, Clark RT, Hayes SR, Edwards J, Cho TW, Wittlake WA: Implementation of a bundle of quality indicators for the early management of severe sepsis and septic shock is associated with decreased mortality. Crit Care Med 2007, 35:1105-1112.

25. Uemura K, Kawada T, Sunagawa K, Sugimachi M: Peak systolic mitral annulus velocity reflects the status of ventricular-arterial couplingtheoretical and experimental analyses. J Am Soc Echocardiogr 2011, 24:582-591. 
26. Robotham JL, Takata M, Berman M, Harasawa Y: Ejection fraction revisited. Anesthesiology 1991, 74:172-183

27. Sturgess DJ, Marwick TH, Joyce C, Jenkins C, Jones M, Masci P, Stewart D, Venkatesh B: Prediction of hospital outcome in septic shock: a prospective comparison of tissue Doppler and cardiac biomarkers. Crit Care 2010, 14:R44

28. Alam M, Wardell J, Andersson E, Samad BA, Nordlander R: Effects of first myocardial infarction on left ventricular systolic and diastolic function with the use of mitral annular velocity determined by pulsed wave Doppler tissue imaging. J Am Soc Echocardiogr 2000, 13:343-352.

29. Landesberg G, Gilon D, Meroz Y, Georgieva M, Levin PD, Goodman S, Avidan A, Beeri R, Weissman C, Jaffe AS, Sprung CL: Diastolic dysfunction and mortality in severe sepsis and septic shock. Eur Heart J 2011 33:895-903.

30. Dellinger R, Carlet J, Masur H, Gerlach H, Calandra T, Cohen J, GeaBanacloche J, Keh D, Marshall JC, Parker M, Ramsay G, Zimmerman JL, Vincent JL, Levy MM, Surviving Sepsis Campaign Management Guidelines Committee: Surviving Sepsis Campaign guidelines for management of severe sepsis and septic shock. Crit Care Med 2004, 32:858-873.

31. Dünser MW, Takala J, Ulmer H, Mayr VD, Luckner G, Jochberger S, Daudel F, Lepper P, Hasibeder WR, Jakob SM: Arterial blood pressure during early sepsis and outcome. Intensive Care Med 2009, 35:1225-1233.

32. Abuelo JG: Normotensive ischemic acute renal failure. N Engl J Med 2007, 357:797-805

doi:10.1186/cc11328

Cite this article as: Weng et al:: The prognostic value of left ventricular systolic function measured by tissue Doppler imaging in septic shock.

Critical Care 2012 16:R71.

\section{Submit your next manuscript to BioMed Central and take full advantage of:}

- Convenient online submission

- Thorough peer review

- No space constraints or color figure charges

- Immediate publication on acceptance

- Inclusion in PubMed, CAS, Scopus and Google Scholar

- Research which is freely available for redistribution

Submit your manuscript at www.biomedcentral.com/submit 